\title{
Hemodynamic Functionality of Transfused Red Blood Cells in the Microcirculation of Blood Recipients
}

\author{
Gregory Barshtein ${ }^{1}$, Dan Arbell ${ }^{2}$ and Saul Yedgar ${ }^{1 *}$ \\ ${ }^{1}$ Department of Biochemistry, Faculty of Medicine, Hebrew University, Jerusalem, Israel, ${ }^{2}$ Department of Pediatric Surgery, \\ Hadassah University Hospital, Jerusalem, Israel
}

\section{OPEN ACCESS}

Edited by:

Joseph M. Rifkind,

Johns Hopkins University,

United States

Reviewed by:

Roland Pittman,

Virginia Commonwealth University,

United States

Dan Predescu,

Rush University, United States

*Correspondence:

Saul Yedgar

yedgar@md.huji.ac.il

Specialty section:

This article was submitted to

Vascular Physiology,

a section of the journal

Frontiers in Physiology

Received: 31 October 2017

Accepted: 11 January 2018

Published: 30 January 2018

Citation:

Barshtein G, Arbell D and Yedgar S (2018) Hemodynamic Functionality of

Transfused Red Blood Cells in the Microcirculation of Blood Recipients.

Front. Physiol. 9:41

doi: 10.3389/fphys.2018.00041
The primary goal of red blood cell (RBC) transfusion is to supply oxygen to tissues and organs. However, due to a growing number of studies that have reported negative transfusion outcomes, including reduced blood perfusion, there is rising concern about the risks in blood transfusion. RBC are characterized by unique flow-affecting properties, specifically adherence to blood vessel wall endothelium, cell deformability, and self-aggregability, which define their hemodynamic functionality (HF), namely their potential to affect blood circulation. The role of the HF of RBC in blood circulation, particularly the microcirculation, has been documented in numerous studies with animal models. These studies indicate that the HF of transfused RBC (TRBC) plays an important role in the transfusion outcome. However, studies with animal models must be interpreted with reservations, as animal physiology may not reflect human physiology. To test this concept in humans, we have directly examined the effect of the HF of TRBC, as expressed by their deformability and adherence to vascular endothelium, on the transfusion-induced effect on the skin blood flow and hemoglobin increment in $\beta$-thalassemia major patients. The results demonstrated, for the first time in humans, that the TRBC HF is a potent effector of the transfusion outcome, expressed by the transfusion-induced increase in the recipients' hemoglobin level, and the change in the skin blood flow, indicating a link between the microcirculation and the survival of TRBC in the recipients' vascular system. The implication of these findings for blood transfusion practice and to vascular function in blood recipients is discussed.

Keywords: microcirculation, red blood cells, blood transfusion, RBC deformability, RBC adhesion, RBC hemodynamic functionality

\section{INTRODUCTION}

Blood transfusion has long been considered a routine life-saving therapy that has revolutionized medicine (Diamond, 1980). Donated blood units, routinely stored as packed red blood cells (PRBC) are routinely stored for up to 35 or 42 days, depending on the preservation solution (Hess, 2006). However, in recent years, there has been a growing concern about the efficacy and safety of the transfusion of allogeneic stored blood (Glynn, 2008; Hillyer et al., 2008; Redlin et al., 2014), as many studies have shown that PRBC transfusion caused damage rather than benefit to recipients. This included prolonged mechanical ventilation, renal failure and sepsis, with increased hospitalization and mortality in transfusion recipients (Sherk et al., 2000; Ho et al., 2003; Gong et al., 2005; Aronson et al., 2008; Glynn, 2008; Hillyer et al., 2008; Koch et al., 2008; Leal-Noval et al., 2008; Marin et al., 2013; Almac et al., 2014; Zimring, 2015). In particular, studies with patients suffering from trauma 
(Weinberg et al., 2012), sepsis (Sakr et al., 2007; Damiani et al., 2015), or thalassemia (Vasileiadis et al., 2013), as well as patients in the medical-surgical intensive care (Creteur et al., 2009), have reported that PRBC transfusion reduced blood perfusion (Sakr et al., 2007; Weinberg et al., 2012), oxygen saturation (Creteur et al., 2009; Vasileiadis et al., 2013), oxygen delivery, and induced tissue hypoxia (Hayes et al., 1994).

Some studies have attributed that to storage-induced lesion to PRBC, showing better outcome with fresher vs. long-stored PRBC (Tinmouth and Chin-Yee, 2001; Gonzalez et al., 2007; Kor et al., 2009; Hess, 2010; D’Alessandro and Zolla, 2013; Damiani et al., 2015; Kim et al., 2015; Obrador et al., 2015; Antonelou and Seghatchian, 2016; Parviz et al., 2016).

However, other studies have not found relation between storage duration and negative transfusion outcome, showing no clinical benefit to using fresher over long-stored RBC (Remy et al., 2016; Shah et al., 2016). The role of storage duration on transfusion outcome is thus still a matter of debate (Lelubre and Vincent, 2013; Brunskill et al., 2015).

Blood donations are routinely tested, on day of donation, for immune compatibility and infectious agents, and are supplied by the first-in-first-out (FIFO) criterion. However, the functionality of transfused RBC, namely their ability to affect the transfusion outcome is ignored. RBC transfusion is aimed at increasing the recipients' hemoglobin and tissue oxygenation. However, RBC have unique flow-affecting properties, which play a key role in blood circulation, and define their hemodynamic functionality, namely their capacity to affect the recipients' blood circulation. The present review focuses on the role of transfused RBC FP on the recipients' blood circulation.

\section{RBC FLOW-AFFECTING PROPERTIES (FP) IN BLOOD CIRCULATION}

RBC FP refer mainly to the cells' deformability, potential adherence to blood vessel all endothelium, and self-aggregability (Shiga et al., 1990; Barshtein et al., 2007; Simmonds et al., 2013).

RBC deformability is the cells' ability to adapt their shape to enable their passage through microvessels, especially the capillaries, which are narrower than the RBC. Reduced deformability (increased rigidity) hinders blood perfusion and impairs oxygen delivery in peripheral tissues (Parthasarathi and Lipowsky, 1999; Sakr et al., 2007; Matot et al., 2013). Rigid $\mathrm{RBC}$ can attenuate perfusion in peripheral tissues and directly block microvessels, capillaries in particular (Mchedlishvili, 1998; Cabrales, 2007). It has been shown that exchange transfusion of rigid, aldehyde-fixated RBC reduced the flow rate in swine (Pantely et al., 1988), and the functional capillary density in hamsters (Cabrales, 2007). RBC deformability is also a major determinant of their passage through the splenic vasculature; reduced deformability hinders the cells passage and increases splenic RBC sequestration and destruction (Warkentin et al., 1990; Mohandas and Chasis, 1993; An and Mohandas, 2008; Huang et al., 2014).

RBC adherence to endothelial cells (EC) of the blood vessel walls ("adherence") is normally insignificant, but it is abnormally enhanced in many disease states. $\mathrm{RBC} / \mathrm{EC}$ adhesion decreases blood flow and increases the residence time of $\mathrm{RBC}$ in the microcirculation (Yedgar et al., 2008). Enhanced RBC/EC adhesion contributes to microcirculatory disorders observed in diverse pathologies, particularly those associated with oxidative stress (OS). In particular, it has been suggested that micro-vessel occlusion observed in sickle cell disease and malaria, especially cerebral malaria, is due to the adherence of sickle/malariainfected RBC to EC of the micro-vessel wall (Yedgar et al., 2008). $\mathrm{RBC} / \mathrm{EC}$ adherence is thus considered a potent catalyst of microvessel occlusion (Hebbel et al., 1981; Kaul and Nagel, 1993; Kaul et al., 1998, 2008; Hebbel, 2000).

RBC aggregability refers to the cells' ability to form multi-cellular aggregates, normally in a rouleau shape, in the presence of plasma proteins, especially fibrinogen, or other macromolecules (Skalak et al., 1981; Barshtein et al., 2007). Under normal conditions, the flow-induced shear stress is sufficient to modulate the aggregation as physiologically required to enable adequate blood flow in the diverse blood vessels. However, in pathological states, mainly those with low-flow or $\mathrm{RBC}$ abnormalities, aggregates that are larger and stronger-thannormal are formed, and higher shear stress is required for their disaggregation (Chen et al., 1995; Ami et al., 2001). Elevated RBC aggregation has been shown to be associated with cardio-vascular diseases (Mohandas and Chasis, 1993; Barshtein et al., 2007), and found to be correlated well with inflammatory indices of patients with unstable angina, myocardial infarct and sepsis (Ami et al., 2001). Increased RBC aggregation elevates blood viscosity and is associated with the formation of an RBC-free layer at the wall of large blood vessels. Accordingly, some studies suggested that the increased viscosity elevates vascular resistance. However, other studies suggested that RBC aggregation facilitates blood flow due to the formation of a cell-free layer at the vessel wall. In addition the viscosity-elevated shear stress leads to the production of the vasodilator nitric oxide (Kim et al., 2006, 2009; Namgung et al., 2011; Cho et al., 2015; Katanov et al., 2015; Ng et al., 2016). These led to disparate views as to the role of RBC aggregation in circulatory functions and disorders.

It is well known that pathological conditions or experimental treatments of RBC usually affect multiple properties, whereas the studies of RBC FP have generally focused on one property at a time, thereby leaving the derivation of the specific, differential effect of individual FP unclear.

This question was specifically addressed in a study, in which the adherence of human RBC was differentially elevated by treatment with $\mathrm{H}_{2} \mathrm{O}_{2}$ concentration that increased the adherence without affecting the deformability. The perfusion of these RBC into rat mesocecum, in a medium which did not induced aggregation (free of macromolecules) induced a considerable elevation of vascular resistance in rat mesocecum (Kaul et al., 2008). In another study (Matot et al., 2008), rat blood was stored for 7 days, during which its RBC deformability was markedly decreased, while their adherence and aggregation were insignificant, which is typical of rat RBC (Schlager et al., 2010). The perfusion of this blood to rats reduced the liver oxygenation, which led to liver necrosis. These studies (Kaul et al., 2008; Matot et al., 2008) thus provide direct evidence 
for the independent contribution of $\mathrm{RBC} / \mathrm{EC}$ adherence and deformability to circulatory disorders.

Notably, RBC aggregates, even with the high aggregability observed in pathological conditions, can be disaggregated by a relatively low shear stress, such as $3-4$ dynes $/ \mathrm{cm}^{2}$, while a RBC with increased adherence or reduced deformability might remain adherent or rigid at a shear stress of $30-40$ dynes $/ \mathrm{cm}^{2}$ (Yedgar et al., 2008). It thus seems that the potency of RBC aggregation to induce vascular occlusion is much less significant.

\section{TRANSFUSION OF PRBC AND RECIPIENTS' MICROCIRCULATION}

The effect of PRBC transfusion on the recipients' blood circulation has been investigated in numerous studies, which together presented inconclusive, even opposing results.

Nielsen et al. (2017) reviewed 17 studies to examine whether or not PRBC transfusion improves tissue oxygenation and/or the microcirculation in critically ill patients. They concluded that the heterogeneity of study designs, methodologies and study populations did not enable an appropriate meta-analysis. Yet, in the majority of cases, RBC transfusion failed to result in significant improvement in either tissue oxygenation or microcirculatory flow in ICU patients.

A number of studies have made attempts to answer the question whether the microcirculatory response to the transfusion is sensitive to the storage duration of the transfused PRBC (Walsh et al., 2004; Bennett-Guerrero et al., 2009; Kiraly et al., 2009; Weinberg et al., 2013; Yürük et al., 2013; Stowell et al., 2017). While some studies reported that long-stored units impaired circulatory functions, such as gastric mucosal oxygenation status (Marik and Sibbald, 1993), and perfused capillary vascular density (Weinberg et al., 2013), others have not observed a significant correlation between the PRBC storage duration and the transfusion-induced change in the recipients' circulatory functions (Walsh et al., 2004; Stowell et al., 2017).

\section{ROLE OF RECIPIENTS' \\ PRE-TRANSFUSION CONDITIONS IN TRANSFUSION-INDUCED CHANGE IN CIRCULATORY FUNCTIONS}

On these grounds, of particular interest are the studies that pointed to the pre-transfusion conditions of the patients as an important factor in the transfusion-induced change in the recipients' circulation. These studies (Casutt et al., 1999; Sakr et al., 2007; Creteur et al., 2009; Sadaka et al., 2011; Weinberg et al., 2012) have suggested that patients who had lowered tissue oxygenation or microcirculatory flow indices prior to transfusion, have benefitted by the transfusion, showing a significant improvement in these indices. Conversely, patients who had normal values of these indices showed either no improvement or a decline after transfusion.

This is further supported by our recent study, showing that the transfusion-induced change in the recipients' skin blood flow $(\triangle \mathrm{SBF})$ was inversely related to the recipients' SBF before transfusion $\left(\mathrm{SBF}_{\mathrm{B}}\right) . \triangle \mathrm{SBF}$ decreased, and was even negative, with increasing $\mathrm{SBF}_{\mathrm{B}}$ (Barshtein et al., 2016). This implies that patients with the most severe tissue oxygenation or microcirculatory derangements (prior to transfusion) benefit the most from the transfusion.

This phenomenon also provides partial explanation for the discrepancy between the above studies showing opposing effects of PRBC transfusion on the recipients' blood circulation (Friedlander et al., 1998; Sakr et al., 2007).

RBC deformability had been shown to decrease in critically ill patients (Friedlander et al., 1998). As noted above, RBCs with decreased deformability are assumed to hinder the passage through the microvessels. However, Friedlander et al. found that the RBC deformability of transfused septic patients was elevated by the PRBC transfusion, and suggested that this improvement is due to the replacement of previously rigidified cells with newer, more functional RBCs (Friedlander et al., 1998). Hence, transfusion may be deleterious in patients with adequate RBC deformability, but may have positive outcome in patients with reduced $\mathrm{RBC}$ deformability.

The mechanism of this phenomenon is not fully understood, but we can speculate that for patients with relatively rigid RBC, such as those with critical illness, e.g., sepsis (Baskurt et al., 1998; Condon et al., 2003; Donadello et al., 2015), the transfusion of PRBCs may enter to the bloodstream RBC with relatively higher deformability, resulting in the improvement of microcirculatory perfusion (Friedlander et al., 1998). This points to the effect of PRBC FP on circulatory functions in transfusion recipients.

\section{ROLE OF TRANSFUSED RBC FLOW-AFFECTING PROPERTIES (FP) IN TRANSFUSION-INDUCED CHANGE IN RECIPIENTS' BLOOD CIRCULATION}

As noted above, the experimental evidence in animal studies supports the hypothesis that FP of transfused RBC are important determinants of the transfusion outcome, especially the recipients' blood microcirculation. However, as already stated, "animal studies must be interpreted with a number of caveats, as animal biology may not reflect human biology" (Zimring, 2015).

To bridge this gap, we directly studied, for the first time in humans, the effect of the HF of TRBC, expressed by their deformability and adherence, on the immediate transfusion outcome. This was measured by the transfusion-induced change in the recipients' skin blood flow, $\triangle \mathrm{SBF}$, determined by the difference in $\mathrm{SBF}$ before $\left(\mathrm{SBF}_{\mathrm{B}}\right)$ and after transfusion. In this study we employed $\beta$-thalassemia major (TM) patients, who are treated with long-life, frequent blood transfusions (every 2-4 weeks). It was clearly found that $\triangle \mathrm{SBF}$ increased with increasing deformability of the TRBC (Barshtein et al., 2016). This was further supported by the data of the individual patients who received four consecutive transfusions over a period of 8-10 weeks. For each of the nine patients, $\triangle \mathrm{SBF}$ increased with increasing TRBC deformability (Barshtein et al., 2016). In some cases, when the TRBC deformability was low and $\mathrm{SBF}_{\mathrm{B}}$ 
was relatively high, the transfusion reduced the recipients' SBF $(\Delta \mathrm{SBF}<0)$ (Barshtein et al., 2016).

In another study (unpublished), we have found that $\triangle \mathrm{SBF}$ depended on the difference in deformability and adherence between the TRBC and the recipients RBC; when the PRBC adherence/rigidity were lower than those of the recipients' RBC, the recipients' blood flow was increased $(\Delta \mathrm{SBF}>0)$. Conversely, when the TRBC rigidity/adherence was higher, the recipients' blood flow was decreased $(\triangle \mathrm{SBF}<0)$. This corresponds to the suggestion of Friedlander et al. (1998) that PRBC transfusion to critically ill patients improved their blood circulation, as their $\mathrm{RBC}$ deformability is especially low.

Taken together, these findings demonstrate, for the first time in humans, the important role of the hemodynamic functionality of transfused RBC, as expressed by their FP, in transfusion outcome.

\section{TRANSFUSED RBC HEMODYNAMIC FUNCTIONALITY AND VASCULAR FUNCTION}

Transfused RBC (TRBC) can modulate vascular function in differing and opposing ways via their effect on the plasma NO level. On one hand, TRBC may induce vasodilation in two ways: the release of ATP, which activates NO production in the blood vessel wall endothelial cells (EC) (Cao et al., 2009; Cortese-Krott and Kelm, 2014; Sikora et al., 2014), and the direct release of NO from the $S$-nitrosylated hemoglobin (SNO-Hb) (BennettGuerrero et al., 2007; Reynolds et al., 2007). On the other hand, a significant part of the TRBC are hemolyzed in the vascular system shortly after transfusion, and release free $\mathrm{Hb}$, which is a scavenger of NO, thereby exerting vasoconstriction (Rusak et al., 2014; Damiani et al., 2015). Notably, the lysis of TRBCs has been

\section{REFERENCES}

Almac, E., Bezemer, R., Hilarius-Stokman, P. M., Goedhart, P., de Korte, D., Verhoeven, A. J., et al. (2014). Red blood cell storage increases hypoxiainduced nitric oxide bioavailability and methemoglobin formation in vitro and in vivo. Transfusion 54, 3178-3185. doi: 10.1111/trf. 12738

Ami, R. B., Barshtein, G., Zeltser, D., Goldberg, Y., Shapira, I., Roth, A., et al. (2001). Parameters of red blood cell aggregation as correlates of the inflammatory state. Am. J. Physiol. Heart Circ. Physiol. 280, H1982-H1988. doi: 10.1152/ajpheart.2001.280.5.H1982

An, X., and Mohandas, N. (2008). Disorders of red cell membrane. Br. J. Haematol. 141, 367-375. doi: 10.1111/j.1365-2141.2008.07091.x

Antonelou, M. H., and Seghatchian, J. (2016). Insights into red blood cell storage lesion: toward a new appreciation. Transfus. Apher. Sci. 55, 292-301. doi: 10.1016/j.transci.2016.10.019

Aronson, D., Dann, E. J., Bonstein, L., Blich, M., Kapeliovich, M., Beyar, R., et al. (2008). Impact of red blood cell transfusion on clinical outcomes in patients with acute myocardial infarction. Am. J. Cardiol. 102, 115-119. doi: 10.1016/j.amjcard.2008.03.027

Barshtein, G., Ben-Ami, R., and Yedgar, S. (2007). Role of red blood cell flow behavior in hemodynamics and hemostasis. Expert Rev. Cardiovasc. Ther. 5, 743-752. doi: 10.1586/14779072.5.4.743

Barshtein, G., Pries, A. R., Goldschmidt, N., Zukerman, A., Orbach, A., Zelig, O., et al. (2016). Deformability of transfused red blood cells is a potent determinant shown to correlate with the fraction of the rigid, undeformable RBC in the TRBCs (Orbach et al., 2017), and transfusion of rigid PRBC causes elevation of cell-free $\mathrm{Hb}$ level in the bloodstream (Damiani et al., 2015).

Taken together, the HF of TRBC seems to play a complex role in modulating vascular function, which seems to depend on the ratio between the cells with normal HF and those with impaired HF. Yet, further investigation is required to elucidate this complex mechanism.

\section{CONCLUSION}

The findings and considerations summarized above demonstrate the important role played by the HF of TRBC in the response of the recipients' vascular function. However, this is a complex response consisting of various effects of the deformability and adherence of the transfused RBC. These include direct effects on blood flow, primarily in the microcirculation, and their differing and opposing effects on vaso-modulation.

The present review presents direct evidence, in animal models and in humans, that the HF of transfused PRBC, as expressed primarily by their deformability and adherence to EC, is a potent effector of transfusion outcome. This strongly supports the need for considering the hemodynamic quality of transfused RBC in blood banking. The assessment of PRBC HF would introduce a powerful tool for reducing transfusion-related risks and improving transfusion therapy.

\section{AUTHOR CONTRIBUTIONS}

GB, DA, and SY have been involved in the analysis and discussion of studies relating to the subject and in the writing of the review. of transfusion-induced change in recipient's blood flow. Microcirculation 23, 479-486. doi: 10.1111/micc. 12296

Baskurt, O. K., Gelmont, D., and Meiselman, H. J. (1998). Red blood cell deformability in sepsis. Am. J. Respir. Crit. Care Med. 157, 421-427. doi: 10.1164/ajrccm.157.2.9611103

Bennett-Guerrero, E., Stafford-Smith, M., Waweru, P. M., Bredehoeft, S. J., Campbell, M. L., Haley, N. R., et al. (2009). A prospective, double-blind, randomized clinical feasibility trial of controlling the storage age of red blood cells for transfusion in cardiac surgical patients. Transfusion 49, 1375-1383. doi: 10.1111/j.1537-2995.2009.02152.x

Bennett-Guerrero, E., Veldman, T. H., Doctor, A., Telen, M. J., Ortel, T. L., Reid, T. S., et al. (2007). Evolution of adverse changes in stored RBCs. Proc. Natl. Acad. Sci. U.S.A. 104, 17063-17068. doi: 10.1073/pnas.0708160104

Brunskill, S. J., Wilkinson, K. L., Doree, C., Trivella, M., and Stanworth, S. (2015). Transfusion of fresher versus older red blood cells for all conditions. Cochrane Database Syst. Rev. 5:CD010801. doi: 10.1002/14651858.CD010801.pub2

Cabrales, P. (2007). Effects of erythrocyte flexibility on microvascular perfusion and oxygenation during acute anemia. Am. J. Physiol. Heart Circ. Physiol. 293, H1206-H1215. doi: 10.1152/ajpheart.00109.2007

Cao, Z., Bell, J. B., Mohanty, J. G., Nagababu, E., and Rifkind, J. M. (2009). Nitrite enhances RBC hypoxic ATP synthesis and the release of ATP into the vasculature: a new mechanism for nitrite-induced vasodilation. Am. J. Physiol. Heart Circ. Physiol. 297, H1494-H1503. doi: 10.1152/ajpheart.01233.2008

Casutt, M., Seifert, B., Pasch, T., Schmid, E. R., Turina, M. I., and Spahn, D. R. (1999). Factors influencing the individual effects of blood transfusions on 
oxygen delivery and oxygen consumption. Crit. Care Med. 27, 2194-2200. doi: 10.1097/00003246-199910000-00021

Chen, S., Gavish, B., Zhang, S., Mahler, Y., and Yedgar, S. (1995). Monitoring of erythrocyte aggregate morphology under flow by computerized image analysis. Biorheology 32, 487-496. doi: 10.3233/BIR-1995-32406

Cho, S., Namgung, B., Kim, H. S., Leo, H. L., and Kim, S. (2015). Effect of erythrocyte aggregation at pathological levels on NO/O2 transport in small arterioles. Clin. Hemorheol. Microcirc. 59, 163-175. doi: 10.3233/CH-141837

Condon, M. R., Kim, J. E., Deitch, E. A., Machiedo, G. W., and Spolarics, Z. (2003). Appearance of an erythrocyte population with decreased deformability and hemoglobin content following sepsis. Am. J. Physiol. Heart Circ. Physiol. 284, H2177-H2184. doi: 10.1152/ajpheart.01069.2002

Cortese-Krott, M. M., and Kelm, M. (2014). Endothelial nitric oxide synthase in red blood cells: key to a new erythrocrine function? Redox Biol. 2, 251-258. doi: 10.1016/j.redox.2013.12.027

Creteur, J., Neves, A. P., and Vincent, J. L. (2009). Near-infrared spectroscopy technique to evaluate the effects of red blood cell transfusion on tissue oxygenation. Crit. Care 13 (Suppl. 5), S11. doi: 10.1186/cc8009

D'Alessandro, A., and Zolla, L. (2013). "Biochemistry of red cell aging in vivo and storage lesion," in Haematology Education: the Education Programme for the Annual Congress of the European Hematology Association (Stockholm: Haematologica), 388-396.

Damiani, E., Adrario, E., Luchetti, M. M., Scorcella, C., Carsetti, A., Mininno, N., et al. (2015). Plasma free hemoglobin and microcirculatory response to fresh or old blood transfusions in sepsis. PLoS ONE 10:e122655. doi: 10.1371/journal.pone.0122655

Diamond, L. (1980). “A history of blood transfusion," in Blood, Pure and Eloquent, ed M. M. Wintrobe (New York, NY: McGraw-Hill Book Company), 659-690.

Donadello, K., Piagnerelli, M., Reggiori, G., Gottin, L., Scolletta, S., Occhipinti, G., et al. (2015). Reduced red blood cell deformability over time is associated with a poor outcome in septic patients. Microvasc. Res. 101, 8-14. doi: 10.1016/j.mvr.2015.05.001

Friedlander, M. H., Simon, R., and Machiedo, G. W. (1998). The relationship of packed cell transfusion to red blood cell deformability in systemic inflammatory response syndrome patients. Shock 9, 84-88. doi: 10.1097/00024382-199802000-00002

Glynn, S. A. (2008). Blood supply safety: an NHLBI perspective. Transfusion 48, 1541-1544. doi: 10.1111/j.1537-2995.2007.01754.x

Gong, M. N., Thompson, B. T., Williams, P., Pothier, L., Boyce, P. D., and Christiani, D. C. (2005). Clinical predictors of and mortality in acute respiratory distress syndrome: potential role of red cell transfusion. Crit. Care Med. 33, 1191-1198. doi: 10.1097/01.CCM.0000165566.82925.14

Gonzalez, A. M., Yazici, I., Kusza, K., and Siemionow, M. (2007). Effects of fresh versus banked blood transfusions on microcirculatory hemodynamics and tissue oxygenation in the rat cremaster model. Surgery 141, 630-639. doi: 10.1016/j.surg.2006.09.015

Hayes, M. A., Timmins, A. C., Yau, E. H., Palazzo, M., Hinds, C. J., and Watson, D. (1994). Elevation of systemic oxygen delivery in the treatment of critically ill patients. N. Engl. J. Med. 330, 1717-1722. doi: 10.1056/NEJM1994061633 02404

Hebbel, R. P. (2000). Blockade of adhesion of sickle cells to endothelium by monoclonal antibodies. N. Engl. J. Med. 342, 1910-1912. doi: 10.1056/NEJM200006223422512

Hebbel, R. P., Moldow, C. F., and Steinberg, M. H. (1981). Modulation of erythrocyte-endothelial interactions and the vasocclusive severity of sickling disorders. Blood 58, 947-952.

Hess, J. R. (2006). An update on solutions for red cell storage. Vox Sang. 91, 13-19. doi: $10.1111 / \mathrm{j} .1423-0410.2006 .00778 . \mathrm{x}$

Hess, J. R. (2010). Red cell storage. J. Proteomics 73, 368-373. doi: 10.1016/j.jprot.2009.11.005

Hillyer, C. D., Blumberg, N., Glynn, S. A., and Ness, P. M. (2008). Transfusion recipient epidemiology and outcomes research: possibilities for the future. Transfusion 48, 1530-1537. doi: 10.1111/j.1537-2995.2008.01807.x

Ho, J., Sibbald, W. J., and Chin-Yee, I. H. (2003). Effects of storage on efficacy of red cell transfusion: when is it not safe? Crit. Care Med. 31, S687-697. doi: 10.1097/01.CCM.0000099349.17094.A3

Huang, S., Amaladoss, A., Liu, M., Chen, H., Zhang, R., Preiser, P. R., et al. (2014). In vivo splenic clearance correlates with in vitro deformability of red blood cells from Plasmodium yoelii-infected mice. Infect. Immun. 82, 2532-2541. doi: 10.1128/IAI.01525-13

Katanov, D., Gompper, G., and Fedosov, D. A. (2015). Microvascular blood flow resistance: role of red blood cell migration and dispersion. Microvasc. Res. 99, 57-66. doi: 10.1016/j.mvr.2015.02.006

Kaul, D. K., Koshkaryev, A., Artmann, G., Barshtein, G., and Yedgar, S. (2008). Additive effect of red blood cell rigidity and adherence to endothelial cells in inducing vascular resistance. Am. J. Physiol. Heart Circ. Physiol. 295, H1788H1793. doi: 10.1152/ajpheart.253.2008

Kaul, D. K., Liu, X. D., Nagel, R. L., and Shear, H. L. (1998). Microvascular hemodynamics and in vivo evidence for the role of intercellular adhesion molecule-1 in the sequestration of infected red blood cells in a mouse model of lethal malaria. Am. J. Trop. Med. Hyg. 58, 240-247. doi: 10.4269/ajtmh.1998.58.240

Kaul, D. K., and Nagel, R. L. (1993). Sickle cell vasoocclusion: many issues and some answers. Experientia 49, 5-15. doi: 10.1007/BF01928783

Kim, E., Kim, H. C., Park, S. Y., Lim, Y. J., Ro, S. H., Cho, W. S., et al. (2015). Effect of red blood cell transfusion on unfavorable neurologic outcome and symptomatic vasospasm in patients with cerebral aneurysmal rupture: old versus fresh blood. World Neurosurg. 84, 1877-1886. doi: 10.1016/j.wneu.2015.08.024

Kim, S., Ong, P. K., Yalcin, O., Intaglietta, M., and Johnson, P. C. (2009). The cell-free layer in microvascular blood flow. Biorheology 46, 181-189. doi: 10.3233/BIR-2009-0530.

Kim, S., Popel, A. S., Intaglietta, M., and Johnson, P. C. (2006). Effect of erythrocyte aggregation at normal human levels on functional capillary density in rat spinotrapezius muscle. Am. J. Physiol. Heart Circ. Physiol. 290, H941-H947. doi: 10.1152/ajpheart.00645.2005

Kiraly, L. N., Underwood, S., Differding, J. A., and Schreiber, M. A. (2009). Transfusion of aged packed red blood cells results in decreased tissue oxygenation in critically injured trauma patients. J. Trauma 67, 29-32. doi: 10.1097/TA.0b013e3181af6a8c

Koch, C. G., Li, L., Sessler, D. I., Figueroa, P., Hoeltge, G. A., Mihaljevic, T., et al. (2008). Duration of red-cell storage and complications after cardiac surgery. $N$. Engl. J. Med. 358, 1229-1239. doi: 10.1056/NEJMoa070403

Kor, D. J., Van Buskirk, C. M., and Gajic, O. (2009). Red blood cell storage lesion. Bosn J. Basic Med. Sci. (9 Suppl 1.), 21-27. doi: 10.17305/bjbms.2009.2750

Leal-Noval, S. R., Munoz-Gomez, M., Arellano-Orden, V., Marin-Caballos, A., Amaya-Villar, R., Marin, A., et al. (2008). Impact of age of transfused blood on cerebral oxygenation in male patients with severe traumatic brain injury. Crit. Care Med. 36, 1290-1296. doi: 10.1097/CCM.0b013e3181692dfc

Lelubre, C., and Vincent, J. L. (2013). Relationship between red cell storage duration and outcomes in adults receiving red cell transfusions: a systematic review. Crit. Care 17: R66. doi: 10.1186/cc12600

Marik, P. E., and Sibbald, W. J. (1993). Effect of stored-blood transfusion on oxygen delivery in patients with sepsis. JAMA 269, 3024-3029. doi: 10.1001/jama.1993.03500230106037

Marin, T., Moore, J., Kosmetatos, N., Roback, J. D., Weiss, P., Higgins, M., et al. (2013). Red blood cell transfusion-related necrotizing enterocolitis in very-lowbirthweight infants: a near-infrared spectroscopy investigation. Transfusion 53, 2650-2658. doi: 10.1111/trf.12158

Matot, I., Cohen, K., Pappo, O., Barash, H., and Abramovitch, R. (2008). Liver response to hemorrhagic shock and subsequent resuscitation: MRI analysis. Shock 29, 16-24. doi: 10.1097/shk.0b013e3180556964

Matot, I., Katz, M., Pappo, O., Zelig, O., Corchia, N., Yedgar, S., et al. (2013). Resuscitation with aged blood exacerbates liver injury in a hemorrhagic rat model. Crit. Care Med. 41, 842-849. doi: 10.1097/CCM.0b013e3182711b38

Mchedlishvili, G. (1998). Disturbed blood flow structuring as critical factor of hemorheological disorders in microcirculation. Clin. Hemorheol. Microcirc. 19, 315-325.

Mohandas, N., and Chasis, J. A. (1993). Red blood cell deformability, membrane material properties and shape: regulation by transmembrane, skeletal and cytosolic proteins and lipids. Semin. Hematol. 30, 171-192.

Namgung, B., Ong, P. K., Johnson, P. C., and Kim, S. (2011). Effect of cell-free layer variation on arteriolar wall shear stress. Ann. Biomed. Eng. 39, 359-366. doi: 10.1007/s10439-010-0130-3

Ng, Y. C., Namgung, B., Leo, H. L., and Kim, S. (2016). Erythrocyte aggregation may promote uneven spatial distribution of $\mathrm{NO} / \mathrm{O} 2$ in the 
downstream vessel of arteriolar bifurcations. J. Biomech. 49, 2241-2248. doi: 10.1016/j.jbiomech.2015.11.051

Nielsen, N. D., Martin-Loeches, I., and Wentowski, C. (2017). The effects of red blood cell transfusion on tissue oxygenation and the microcirculation in the intensive care unit: a systematic review. Transfus. Med. Rev. 31, 205-222. doi: 10.1016/j.tmrv.2017.07.003

Obrador, R., Musulin, S., and Hansen, B. (2015). Red blood cell storage lesion. J. Vet. Emerg. Crit. Care 25, 187-199. doi: 10.1111/vec. 12252

Orbach, A., Zelig, O., Yedgar, S., and Barshtein, G. (2017). Biophysical and biochemical markers of red blood cells fragility. Transfus. Med. Hemother. 44, 183-187 doi: 10.1159/000452106

Pantely, G. A., Swenson, L. J., Tamblyn, C. H., Seaman, G. V., Anselone, C. G., Johnson, W. B., et al. (1988). Increased vascular resistance due to a reduction in red cell deformability in the isolated hind limb of swine. Microvasc. Res. 35, 86-100. doi: 10.1016/0026-2862(88)90052-0

Parthasarathi, K., and Lipowsky, H. H. (1999). Capillary recruitment in response to tissue hypoxia and its dependence on red blood cell deformability. Am. J. Physiol. 277(6 Pt 2), H2145-H2157. doi: 10.1152/ajpheart.1999.277. 6.H2145

Parviz, Y., Hsia, C., Alemayehu, M., Wall, S., Bagur, R., AbuRomeh, N., et al. (2016). The effect of fresh versus standard blood transfusion on microvascular endothelial function. Am. Heart J. 181, 156-161. doi: 10.1016/j.ahj.2016.05.021

Redlin, M., Habazettl, H., Schoenfeld, H., Kukucka, M., Boettcher, W., Kuppe, H., et al. (2014). Red blood cell storage duration is associated with various clinical outcomes in pediatric cardiac surgery. Transfus. Med. Hemother. 41, 146-151. doi: $10.1159 / 000357998$

Remy, K. E., Sun, J., Wang, D., Welsh, J., Solomon, S. B., Klein, H. G., et al. (2016). Transfusion of recently donated (fresh) red blood cells (RBCs) does not improve survival in comparison with current practice, while safety of the oldest stored units is yet to be established: a meta-analysis. Vox Sang. 111, 43-54. doi: $10.1111 /$ vox. 12380

Reynolds, J. D., Ahearn, G. S., Angelo, M., Zhang, J., Cobb, F., and Stamler, J. S. (2007). S-nitrosohemoglobin deficiency: a mechanism for loss of physiological activity in banked blood. Proc. Natl. Acad. Sci. U.S.A. 104, 17058-17062. doi: $10.1073 /$ pnas.0707958104

Rusak, T., Misztal, T., Piszcz, J., and Tomasiak, M. (2014). Nitric oxide scavenging by cell-free hemoglobin may be a primary factor determining hypertension in polycythemic patients. Free Radic. Res. 48, 230-238. doi: 10.3109/10715762.2013.860225

Sadaka, F., Aggu-Sher, R., Krause, K., O’Brien, J., Armbrecht, E. S., and Taylor, R. W. (2011). The effect of red blood cell transfusion on tissue oxygenation and microcirculation in severe septic patients. Ann. Intensive Care 1:46. doi: 10.1186/2110-5820-1-46

Sakr, Y., Chierego, M., Piagnerelli, M., Verdant, C., Dubois, M. J., Koch, M., et al. (2007). Microvascular response to red blood cell transfusion in patients with severe sepsis. Crit. Care Med. 35, 1639-1644. doi: 10.1097/01.CCM.0000269936.73788.32

Schlager, A., Zamir, G., Barshtein, G., Yedgar, S., and Arbell, D. (2010). Plasma factor in red blood cells adhesion to endothelial cells: humans and rats. Cell Biochem. Biophys. 58, 157-161. doi: 10.1007/s12013-010-9102-3

Shah, A., McKechnie, S., Brunskill, S. J., and Stanworth, S. J. (2016). Fresh versus old red cell transfusions: what have the recent clinical trials found? Curr. Opin. Hematol. 23, 550-556. doi: 10.1097/MOH.0000000000000283

Sherk, P. A., Granton, J. T., and Kapral, M. K. (2000). Red blood cell transfusion in the intensive care unit. Intensive Care Med. 26, 344-346. doi: $10.1007 / \mathrm{s} 001340051160$
Shiga, T., Maeda, N., and Kon, K. (1990). Erythrocyte rheology. Crit. Rev. Oncol. Hematol. 10, 9-48. doi: 10.1016/1040-8428(90)90020-S

Sikora, J., Orlov, S. N., Furuya, K., and Grygorczyk, R. (2014). Hemolysis is a primary ATP-release mechanism in human erythrocytes. Blood 124, 2150-2157. doi: 10.1182/blood-2014-05-572024

Simmonds, M. J., Meiselman, H. J., and Baskurt, O. K. (2013). Blood rheology and aging. J. Geriatr. Cardiol. 10, 291-301. doi: 10.3969/j.issn.1671-5411.2013.03.010.

Skalak, R., Zarda, P. R., Jan, K. M., and Chien, S. (1981). Mechanics of Rouleau formation. Biophys. J. 35, 771-781. doi: 10.1016/S0006-3495(81)84826-6

Stowell, C. P., Whitman, G., Granger, S., Gomez, H., Assmann, S. F., Massey, M. J., et al. (2017). The impact of red blood cell storage duration on tissue oxygenation in cardiac surgery. J. Thorac. Cardiovasc. Surg 153, 610-619. doi: $10.1016 /$ j.jtcvs.2016.11.029

Tinmouth, A., and Chin-Yee, I. (2001). The clinical consequences of the red cell storage lesion. Transfus. Med. Rev. 15, 91-107. doi: 10.1053/tmrv.2001.22613

Vasileiadis, I., Basios, N., Gerovasili, N., Dimopoulos, S., Ladis, N., Kompoti, M., et al. (2013). Blood transfusion improves tissue oxygenation in beta-thalassemia major patients. Health Sci. J. 7, 448-453.

Walsh, T. S., McArdle, F., McLellan, S. A., Maciver, C., Maginnis, M., Prescott, R. J., et al. (2004). Does the storage time of transfused red blood cells influence regional or global indexes of tissue oxygenation in anemic critically ill patients? Crit. Care Med. 32, 364-371. doi: 10.1097/01.CCM.0000108878.23703.E0

Warkentin, T. E., Barr, R. D., Ali, M. A., and Mohandas, N. (1990). Recurrent acute splenic sequestration crisis due to interacting genetic defects: hemoglobin SC disease and hereditary spherocytosis. Blood 75, 266-270.

Weinberg, J. A., MacLennan, P. A., Vandromme-Cusick, M. J., Angotti, J. M., Magnotti, L. J., Kerby, J. D., et al. (2012). Microvascular response to red blood cell transfusion in trauma patients. Shock 37, 276-281. doi: 10.1097/SHK.0b013e318241b739

Weinberg, J. A., MacLennan, P. A., Vandromme-Cusick, M. J., Magnotti, L. J., Kerby, J. D., Rue, L. W. III., et al. (2013). The deleterious effect of red blood cell storage on microvascular response to transfusion. J. Trauma Acute Care Surg. 75, 807-812. doi: 10.1097/TA.0b013e3182a74a9b

Yedgar, S., Kaul, D. K., and Barshtein, G. (2008). RBC adhesion to vascular endothelial cells: more potent than RBC aggregation in inducing circulatory disorders. Microcirculation 15, 581-583. doi: 10.1080/10739680802105482

Yürük, K., Milstein, D. M., Bezemer, R., Bartels, S. A., Biemond, B. J., and Ince, C. (2013). Transfusion of banked red blood cells and the effects on hemorrheology and microvascular hemodynamics in anemic hematology outpatients. Transfusion 53, 1346-1352. doi: 10.1111/j.1537-2995.2012.03905.x

Zimring, J. C. (2015). Established and theoretical factors to consider in assessing the red cell storage lesion. Blood 125, 2185-2190. doi: 10.1182/blood-2014-11-567750

Conflict of Interest Statement: The authors declare that the research was conducted in the absence of any commercial or financial relationships that could be construed as a potential conflict of interest.

Copyright (c) 2018 Barshtein, Arbell and Yedgar. This is an open-access article distributed under the terms of the Creative Commons Attribution License (CC BY). The use, distribution or reproduction in other forums is permitted, provided the original author(s) and the copyright owner are credited and that the original publication in this journal is cited, in accordance with accepted academic practice. No use, distribution or reproduction is permitted which does not comply with these terms. 